\title{
Organization of higher education work in the e-education system in Russia
}

\section{Organización del trabajo de educación superior en el sistema de educación electrónica en Rusia}

\author{
EVPLOVA, Ekaterina V. ${ }^{1}$ \\ YAKUPOV, Valeriy R. ${ }^{2}$ \\ DEMTSURA, Svetlana S. ${ }^{3}$ \\ SANNIKOVA, Svetlana V. ${ }^{4}$ \\ LEBEDEVA, Tatiana N. ${ }^{5}$ \\ TYUNIN, Alexander I. 6 \\ ZOLOTUKHIN, Nikolaevich S. ${ }^{7}$
}

\begin{abstract}
The article focuses one-learning in the context of changing goals and the paradigm of Russian e-ducation. The authors present a review of modern researchers main ideas concerning the problem of introducing an information electronic educational environment in the practice of higher education institutions. It is concluded that the implementation of an innovative conceptual model will contribute to the formation and development of a competitive educational organization at the national and international levels.
\end{abstract}

Key words: e-education, higher education, distance education technologies, information educational environment.

\begin{abstract}
Resumen
El artículo se centra en la actualidad del aprendizaje electrónico en el contexto de los objetivos cambiantes y el paradigma de la educación Rusa y presenta una revisión de las ideas principales de ( los) investigadores modernos sobre el problema de introducir un entorno educativo electrónico de información en la práctica de las instituciones de educación superior. Se concluye que la implementación de un modelo conceptual innovador contribuirá a la formación y desarrollo de una organización educativa competitiva a nivel nacional e internacional.

Palabras clave: educación electrónica, educación superior, tecnologías de educación a distancia, entorno educativo informativo.
\end{abstract}

\footnotetext{
${ }^{1}$ South Ural State Humanitarian Pedagogical University, Department of Economics, Management and Law, Chelyabinsk, Russia, Candidate of Pedagogical Science, Associate Professor. e-mail: akadem-ppi@mail.ru

${ }^{2}$ South Ural State Humanitarian Pedagogical University, Department of Economics, Management and Law, Chelyabinsk, Russia, Candidate of Law Science, Associate Professor

${ }^{3}$ South Ural State Humanitarian Pedagogical University, Department of Economics, Management and Law, Candidate of Pedagogical Science, Associate Professor

${ }^{4}$ South Ural State Humanitarian Pedagogical University, Department of Foreign Languages, Chelyabinsk, Russia, Candidate of Pedagogical Science, Associate Professor

${ }^{5}$ South Ural State Humanitarian Pedagogical University, Department of Informatics, Informatics Technology and Methodology of Teaching Informatics, Candidate of Pedagogical Science, Associate Professor

${ }^{6}$ South Ural State Humanitarian Pedagogical University, Department of Economics, Management and Law, Chelyabinsk, Russia, Candidate of Pedagogical Science, Associate Professor

${ }^{7}$ South Ural State Humanitarian Pedagogical University, Department of Economics, Management and Law, Chelyabinsk, Russia, Candidate of Law Science, Associate Professor
} 


\section{Introduction}

In our fast-paced time, once popular Omar Khayyam statement "he, who saw life, does not hurry" no longer corresponds to a modern person life tempo. The slightest lag behind the development rhythms set by the state, society, as well as by the information and communication technologies and the scientific and technological progress can take many steps back especially when it comes to work in the higher education system.

In connection with this, one of the main tasks of the modern education is an effective use of e-learning opportunities. However, the analysis of theoretical developments in this direction and pedagogical practice result in our conclusion that the electronic environment capabilities are not fully used. The features of the work organization of higher education institutions in the e-education system are not fully considered. For this reason, in our opinion, it is necessary to use a system approach to solve this problem.

Demtsura indicates that the strategy of socio-economic development of Russia until 2025 determines the need for a transition to an innovative model. This model reflects the necessity for changes in the system of higher professional education (Demtsura et al., 2019).

The implementation of educational programs using e-learning and distance learning technologies is a focused process of interaction of educators and students with each other and with learning tools, which is implemented in a specific didactic system (Popova, 2015).

The early 20th century is known to be characterized by a significant economic growth in almost all the countries; by 1913, agrarian Russia not only caught up but also overtook the industrial countries of the European continent in some spheres. Both telegraph and telephone communications were widely used in the organization of training.

However, those means of communication did not stimulate the development of e-learning. Only in the middle of the 20th century, when television was invented, the immediate precursor of electronic education - television educational programs - appeared.

Contemporaries of those events may remember the way the television lessons were broad-casted. As a rule, the themes never coincided with the current school programs but at that time this innovation seemed to be an extraordinary progress. Undoubtedly, the disadvantages of such training are obvious now; they were one-sided and uncontrolled links. That is why there occurred grounded doubts regarding the appropriateness and quality of this type of training.

The first personal computers automated learning in the 1980s. Training programs were developed in the form of games and computer programs. Without leaving home everyone could take training courses according to his or her interests.

Nowadays, e-learning gained credibility not only among young people. When retiring, those wishing to acquire new knowledge, that was not available before, turn to e-learning.

This form of education is undoubtedly almost the only one for disabled children and adults; for young mothers who have nobody else to take care of their children for some time; for the retired, etc. E-learning removes the problem of long-distance travel in case the educational institution is located far from the student's place of residence.

A student who has chosen this method of learning is largely independent in organizing, planning and monitoring his or her study. Also, thanks to e-learning one can study several courses at one and the same time.

However, e-learning has its drawbacks. First of all, students should be very motivated. Not everyone can plan the learning process independently and not everyone has skills of self-control and self-organization. 
Other problems include the lack of the Internet in remote countries / cities / towns, computer illiteracy and student identification issues as it is rather difficult to find out if it is the registered person that has the exam or test.

The advantages of e-learning clearly prevail. Due to the increasing demand for educational services and the development of information technologies, this form of training will be more and more popular every year.

It should also be underlined that education is traditionally considered to be a very conservative field, but the development of technology changes people's ideas of getting necessary knowledge and makes them reconsider the usual approach to the educational system.

First, teaching tools using information technologies begin being used in education: on-line courses, simulators, on-line game worlds, on-line conferences, on-line chat rooms. This gives new opportunities for students, they not only learn necessary material but also develop informational abilities. They also learn to solve complex creative and analytical problems. In a state of flow, when a person is fully involved into the creative process does not experience the anxiety concerning possible success or failure.

Second, new technologies make electronic education more personal. There is no longer any need to adapt to the general schedules and group demands. Today the learning process is quite easily adapted to the needs of a particular student and his/her personal characteristics. You can choose the format of training and its pace, concentrate on a very narrow theme or, on the contrary, learn some interdisciplinary program.

Distance is not a problem because now one can take on-line courses at many prestigious universities living anywhere in the world. In short time distance education will become an equal alternative to traditional full-time education, and "electronic tutors" will observe the educational process and help students master the program.

With the transition to an e-learning educational system, the didactic tools also change. Audience becomes a virtual educational environment, presentations and slideshows are replaced with flip-charts, and students already use the Word Document on a personal computer instead of the traditional exercise books.

Thus, the world is changing so quickly that would-be specialists will no longer be able to afford several years to study theoretical disciplines and master the profession. Therefore, education, especially for university students, for advanced and retraining courses, is becoming more substantive and practice-oriented. It means that the emphasis is shifting from the theory obtained within educational organizations to the practice acquired through e-education. In addition, forms of binary education are developing when a student can study and work simultaneously (Evplova et al., 2019).

The modern world emphasizes the development of an electronic information educational environment due to a special interactive generation of students has been formed. New generation requires a different approach to the educational process; so it is necessary to create a modern electronic environment of institutions that meets the demands and needs of the modern generation. In our opinion, the successful use of e-learning depends on the availability of a developed information and educational environment which should contain academic content of high-quality in the form of on-line courses and teaching materials, an interactive environment, and an automated system for processing and storing training results. Making creative communication space basing on scientific and economic foundation will be more effective if the basic principles of e-learning are carried out.

The problem of organizing work of higher Institutions in the e-education system is widely studied abroad. Scholars studying this issue are M.G. Blight, E.K. Ruppel, K.V. Schoenbauer (Blight et al., 2017), A. Droppe, B. Soderfeldt (Droppe et al., 2010), A.J. Garcia-Martinez, C. Gutierrez-Hita, J. Sanchez-Soriano (Garcia-Martinez et al., 2012), J. Pike, P. Bateman, B. Butler (Pike et al., 2012), Tang Shi-Ming, Shi Fang-Miao, Chen Xi. (Tang Shi-Ming et al., 2015), E. Frison, S. Eggermont (Frison et al., 2017), R.B. King, D.M. Mclnerney, D.A. Watkins (King et al., 2012) and others. Studying the influence of cyber space on modern youth has also become popular among foreign scholars (M.A. Wakefield, C.J. Rice (Wakefield et al., 2008), F. Jafarzadeh-Kenarsari, P. Pourghane 
(Jafarzadeh-Kenarsari et al., 2017), D.M. Boyd, N.B. Ellison (Boyd et al., 2007), J. Field (Field et al., 2008) and others).

Thus, in the survey by E. Frison and S. Eggermont, different ways of using a social network are considered (Frison et al., 2017). In their publication, M. G. Blythe, E. K. Ruppel and K. V. Schönbauer consider communities in the on-line space, as well as the role of motives of the Internet users and their para social relationships (Blight et al., 2017). A. Cohn also examines the Internet as a naturalized propaganda tool (King et al., 2012).

In their article, J. Pike, P. Bateman and B. Butler study the behavior of young people in the Internet space, selfpresentation and the formation of a positive impression in the hiring process (Pike et al., 2012).

The results of a specially conducted survey reflecting the opinions of the younger generation concerning the Internet environment are presented in the work of a domestic researcher M.Yu. Semenov (Semenov, 2018).

A number of Russian researchers study the competitiveness of educational organizations through introduction of the e-learning system (V.A. Veshchevatykh (Veshchevatykh, 2007), N.V. Zhukova (Zhukova, 2006), I. Loginova (Loginova, 2015), K.B. Prigozhina, K.V. Trostina (Prigozhina et al., 2017) and others). All of the above mentioned researchers consider the competitiveness of the university through the e-learning system development.

It should be pointed out that within the Russian academic community, in contrast to the experience of Western colleagues, the issue of higher education institutions work organizing in the e-learning system is still poorly developed despite the fact that recently electronic educational resources have been widely introduced into the practice of Russian educational institutions and educational programs are widely spread being implemented through e-learning and distance learning technologies.

\section{Methodology}

The facts presented above are confirmed by the presence of a regulatory framework developed in Russia and internationally and regulating the issues of the work organization of higher education institutions in the electronic and distance education system.

In Russia, the concept of "distance learning technologies" was introduced into legal circulation in 2003 by the Russian Federation Law "On Education". Initially, distance learning technologies were referred to as educational technologies put into practice mainly through using information and television network providing completely or incompletely mediated interaction between the teacher and the student.

The Methodology of using distance learning technologies (distance learning) in educational institutions of higher, secondary and additional professional education, adopted by the Ministry of Education of the Russian Federation to provide methodological assistance in the use of information technologies, came into force. In this document, distance learning was associated with distance educational technologies providing targeted indirect (as well as not completely indirect) interaction between the student and the teacher without taking into account space factors (their location) and time factors (the moment each of them begins interacting). At the same time, this Methodology determined the list of the main distance educational technologies that can be applied by the indicated educational organizations - case technology, the Internet technology and telecommunication technology.

\subsection{Evolution of e-learning in Russia}

Russian educational institutions were allowed to use distance learning both fully or partly (i.e. at least $70 \%$ of the curriculum are carried out through distance learning technologies) for any form of getting education (full-time, part-time (evening), correspondence and external studies) when implementing educational programs. If the educational program is carried out using distance learning only, students entering the educational institution to learn this program should get to know about this circumstance and prove it by their signature. 
Along with traditional information resources the Methodology for using distance learning technologies prescribed the use of distance learning information databases (including basic educational literature funds, periodicals and scientific literature funds) and special distance learning tools (for example, electronic textbooks, educational videos and computer lab workshops). Educational institutions of higher education were required to have a certain number of specially equipped laboratories designed for the use of such educational technologies.

It should be noted that the use of distance learning technologies in Russia was restricted in certain ways: the students' practical work, as well as final certification of graduates could be conducted exclusively through traditional methods (while training practices, ongoing monitoring and intermediate certification of students could be carried out using electronic tools).

It is important to emphasize that educational institutions in Russia are not required to obtain a special license for the use of distance learning technologies in the implementation of educational programs. Moreover, if a graduate studied an educational program through distance learning only, a record concerning this was made at the bottom of the diploma supplement back. In 2005, the requirements for educational institutions using distance learning technologies became more strict in Russia at the legislative level: now they should (but did not have the right, as earlier) have executive and pedagogical staff as well as supporting staff having a certain training level corresponding to implementation of such educational technologies. For this purpose educational institutions organized advanced training courses for those workers.

In late 2011, it was pointed out at the state level that one of the key directions for improving the quality of education is expanding the use of e-learning. In 2012, the concept of "e-learning" was introduced into legal circulation and it became possible to implement it in all forms of getting education in Russia under any educational programs; and the requirements for using distance learning technologies in the e-learning educational process were clarified.

E-learning came to mean the organization of the educational process using: 1) information contained in the databases and used in the implementation of educational programs; 2 ) information technologies and technical means providing the processing of such information; 3) information and telecommunication networks that ensure sending specified information by means of communication links and interaction of the educational process participants. Thus, while in Russia at the legislative level, remote educational technologies are referred to as educational technologies allowing indirect (distance) interaction between teachers and students, then elearning is an educational process based on the use of information systems and information and telecommunication networks.

In 2012, the concept of an electronic information and educational environment was also introduced in Russia at the legislative level. For its functioning all the necessary conditions should be created in educational institutions in case educational programs are implemented exclusively through e-learning and distance educational technologies.

In 2014, it is allowed at the legislative level to use e-learning and distance learning technologies not only for conducting training but also for all types of practices, ongoing monitoring, intermediate and even final (state final) certification of students. Moreover, classes where students should be present can be not conducted now.

In 2020, the situation with the use of e-learning in Russian education was radically influenced by the measures taken at the state level to combat the spread of the new corona-virus infection COVID-19. Educational institutions are instructed to organize contact work of students and teachers exclusively in the electronic information and educational environment. Gradually, all educational institutions closed their doors to students and started a remote format of working.

However, despite the significant progress within the last decade, Russia is still lagging behind in terms of the legal regulation of e-learning. For the time being, there is no state strategy in the field of development of e-learning in Russia. At the same time, since 2012, many countries including USA, Australia, Great Britain and Brazil declared 
the creation of large-scale national projects in the field of e-education. In these countries, on-line educational courses unite several universities in educational networks. It is important to underline that these networks are donated exclusively by universities or private investors.

Studying the Russian regulatory framework of higher institutions work, which use the e-education system for a comprehensive solution, we should turn to the modeling method by developing an innovative conceptual model of the organization of higher education institutions using in the e-education system.

Since most of the problems pedagogical science deals with are extremely complex in their content, the construction of a simplified model can reflect the object under study only partially. To examine complex and multidimensional phenomena of pedagogical problems a variety of models are used. The construction of each of the models existing in pedagogical science allows only fragmentary consideration of the individual aspects of the phenomenon under study. For comprehensive examining the object of study, we need to develop an author's concept of effective organization of work in the e-education system. A complex conceptual model of higher education institutions work is capable to examine thoroughly the object under study; allows us to present the subject of research as a complex phenomenon.

The developed model is considered a sample to achieve in the process of organizing higher education institutions work in the e-education system; reflects the structure and interaction of the components, shows the process aimed at solving the problem under study.

\section{Results}

The structural components of the model under consideration reveal the process internal management: the goal, tasks, the main ideas essence, organizational forms and methods - and are responsible for the constant reproduction of the interaction between the elements of this process.

The functional components are stable basic relationships of the structural components, that is, the way of organizing work and functions, thereby determining the movement, development and improvement of the pedagogical system for organizing the work of higher education institutions in the electronic education system.

The developed model specific feature is the unity of the meaningful, procedural and productive aspects of the work organization of higher education institutions in the electronic education system, which is reflected in the model blocks.

Consideration of some aspects of the work organization of higher education institutions in the electronic education system and the identification of structural and functional components resulted in dividing the model into a number of blocks.

In accordance with the identified components, we include the following blocks in the conceptual model of the work organization of higher education institutions in the electronic education system: goal setting block, substantive, procedural, functional and result blocks.

Taking into consideration the logic of the investigation, the first block to specify is the goal-setting one including determining the goal and specific tasks of the work organization of higher education institutions in the electronic education system. (Figure 1). 
Figure 1

The goal-setting block of the author's scheme of the work organization of higher education institutions in the e-Education system
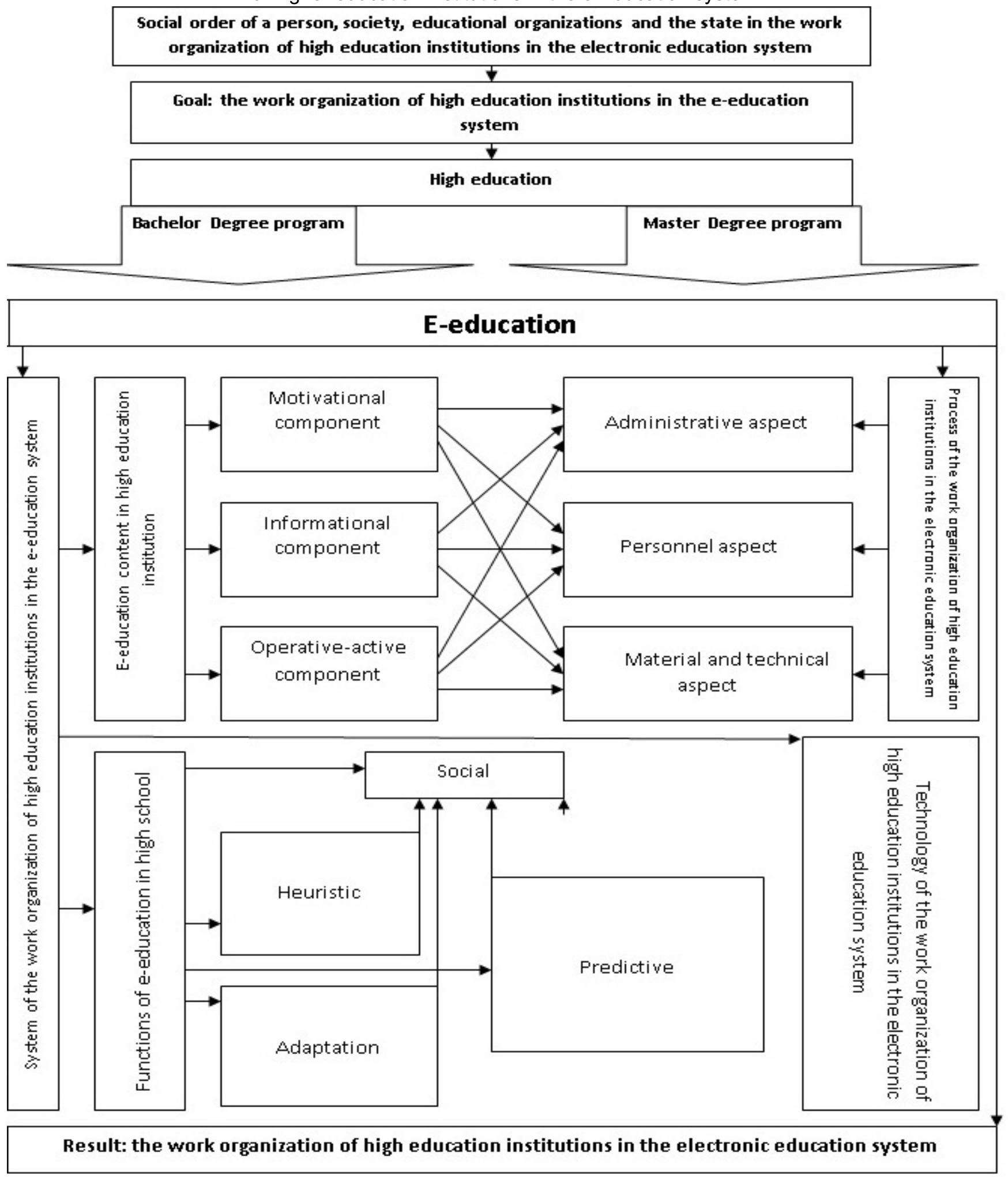

(Evplova E.V. et al.) 
The goal of the work organization of higher education institutions in the e-education system is determined by the social order of a person, society, educational organizations and the state. The goal is specified in the tasks, the wording of which is presented below and in Figure 2 (Fig. 2).

Figure 2

The goal-setting block of the author's scheme of the work organization of higher education institutions in the e-Education system

Goal: the work organization of high education institutions in the electronic education system

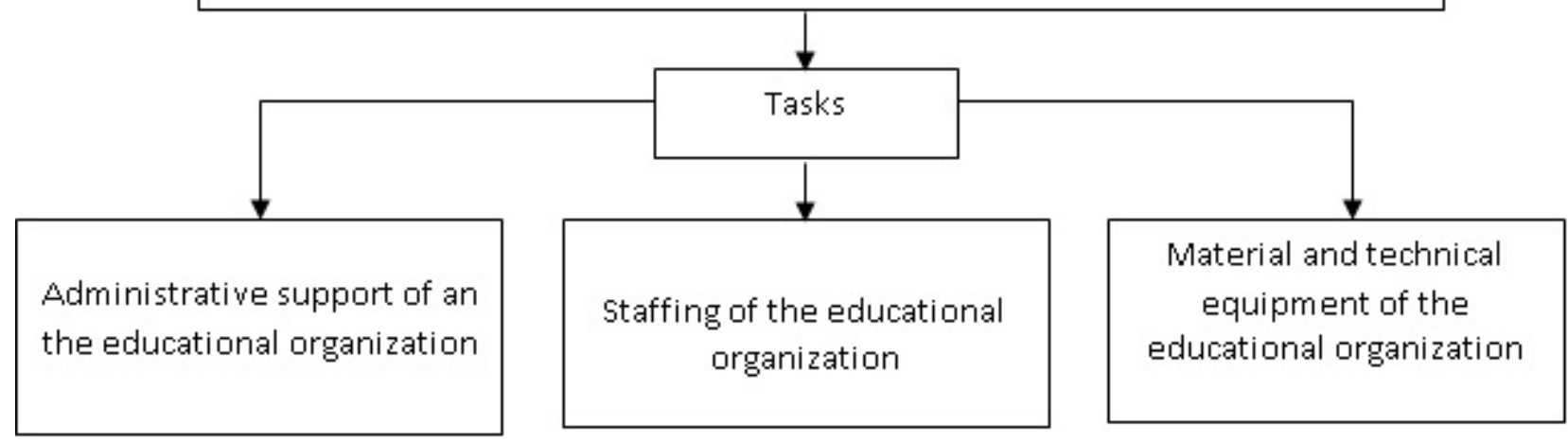

(Evplova E.V. et al.)

The tasks of the work organization of higher education institutions in the electronic education system are the following:

Administrative support of an educational organization(working out local regulatory documentation, payments for teachers and methodologists, development of a quality monitoring and reporting system, and so on).

Personnel support of an educational organization (training and retraining the teaching staff, technical personnel, etc.).

Material and technical facilities of an educational organization (creating an electronic learning environment or an e-learning platform, equipping an educational organization with modern facilities, creating an information and educational environment that includes a set of digital educational resources, a set of information and telecommunication technologies, equipment, high-speed telecommunications, a hardware and software platform, developed electronic educational programs, electronic textbooks and manuals, electronic sources of information, electronic libraries, audio and video materials, testing systems, etc.).

In accordance with the goal setting block of the conceptual model, we consider the substantive, procedural, functional and result blocks separately and show their system connections.

Consideration of the structure, content and functions of the organization of higher education institutions work in the e-education system is predetermined by the expected result that can be obtained through carrying out the work of higher education institutions in the electronic education system.

Taking into account the productive aspect, we examine the structure and content of the form of educational activity under consideration.

There are three levels of higher education: Degree level, Master Degree level and Ph.D level. The main components implemented at each level of the model are the motivational, informational and operative-active component which are the subsystems of electronic education and in their turn have their own content and 
functions. The relationships between the components are carried out at the substantive and functional levels and each of them influences the next one by solving its own problems:

1. Motivational component: The electronic education system should correspond to three levels: 1) at the individual level the demands are formed on the basis of a person's physiological needs and ideas on the quality of life, education, etc.; 2 ) at the level of social production the needs are considered as the initial driving force giving an initial impetus to the production process; 3 ) at the level of the society and state the most important issue is the development of the priorities which should become the basis for creating an optimal, efficient and progressive system of needs in accordance with the electronic education system.

2. Informational part: means the spread of complete and reliable information concerning the work of an educational organization in an e-learning system, willingness and ability to get and process new information concerning the work organization of higher education institutions in the electronic education system and its interaction with the existing awareness in this area.

3. Operative-active component: is organizing educational and cognitive activities of students in order to master education programs in an electronic educational environment.

The interconnection of the presented components of the work organization of higher education institutions in the e-education system can be traced at the functional level. The functions are:

Social: It determines the social role of electronic education in society and the processes of a person's socialization in the digital world. It forms both a social partnership of e-education with the educational structures of the city and the region and values in accordance with the individual abilities of students.

It should be underlined that social function is the main one making all the other functions revolve around itself and establishing the logic of their implementation.

Heuristic: It involves students in various activities in the context of electronic education (video lectures, video conferences, on-line chats, etc.).

Adaptation: It means adaptation of the individual and educational organizations to changing living conditions and the scientific and technological process.

Predictive: It allows to reveal trends in the development of electronic education and contributes to forecasting.

The process of the work organizing of higher education institutions in the e-education system is expressed in three main aspects:

Administrative aspect: In the process of organizing e-education there appear a large number of administrative issues. For example, in what way to organize a system for creating on-line courses within an educational organization and coordinate it with the current regulatory documents; teachers' and methodologists' compensations for the development and maintenance of e-learning; adaptation of the reporting system among others.

Staffing aspects: The implementation of the e-education system includes formation of a new teaching staff having certain skills. Of course, certain requirements are imposed on the authors of on-line courses as well as on the technical staff ensuring the smooth functioning of the equipment necessary for the new educational programs implementation. On-line education is recommended as the best form of taking advanced training courses and retraining of teachers. Such courses should cover both e-learning implementation technology issues and e-pedagogy issues. Their content should include the study of the features of the training platform using, analysis of the high-quality on-line learning criteria, the skills of presenting feedback to students via the Internet, 
conducting discussions and forums, rating student work, encouraging students to study actively through on-line learning and so on, which is reflected in the motivational, informational and operative-active components of the conceptual model. It is advisable to train teachers on the same e-learning platform that is used in the educational organization to work with students. Priority in the process of organizing work with personnel should be given to computer technologies in training and to the Internet resources since this is the basis of the computer literacy of such a teacher.

Material and technical aspects: The system requires the creation of an electronic learning environment or elearning platform for its implementation. The development of an e-learning system requires not only highly qualified specialists and teachers but a modern equipment necessary for the implementation of the new system. Also, a complex of digital educational resources, information and telecommunication technologies, equipment, high-speed telecommunications providing interactive technologies, a software and hardware platform and others requirements. Electronic educational programs, textbooks and manuals, information sources, libraries, audio and video materials, testing systems, etc. In other words, the educational organization should have interactive electronic content for all educational disciplines making up the educational program. The material and technical aspect of the work organization of higher education institutions in the e-learning system can also include automated systems of distance learning / educational process management allowing access to information and educational-methodological support of programs and providing indirect communication.

The conceptual model of the organization of higher school work in the electronic education system presented in this way allows to develop technological support for organizing the work of higher school institutions in the system of e-education and to obtain a result corresponding to a common goal.

\section{Conclusions}

1. The conceptual model of the work organization of higher education institutions in the electronic education system is a structural-functional model the specific feature of which is the unity of the substantive, procedural and productive aspects, which is reflected in the blocks of the model.

2. The purpose of organizing the work of higher education institutions in the electronic education system is determined by the social order of a person, society, educational organizations and the state.

3. The main substantive components of the work organization of higher education institutions in the electronic education system are motivational, informational and operative-active components which are the subsystems of electronic education, have their own structure and functions - social, heuristic, adaptive and predictive and are reflected in three main aspects - administrative, personnel, material and technical.

Creating an innovative functional educational model for organizing the process of the work of higher school institutions in the e-learning system should contribute to the formation of a competitive person orienting himself or herself in the modern educational electronic environment.

Thus, an effectively managed system of e-education is one of the important factors of the innovative development of the modern education in general and higher education in particular. E-education, which is increasingly considered to be a new education paradigm of the 21st century, should become a priority for the development of the higher education system in the context of globalization, socialization of services and technologies and mass use of the Internet.

It can be predicted that scientific knowledge in the field of organizing the work of higher education institutions in the electronic education system will be actively accumulated in the near future and practically applied to 
increase the educational system effectiveness. The related sciences, primarily pedagogy, psychology and computer science, will receive a new impetus in their development.

This work was financially supported by a grant from Shadrinsk State Pedagogical University (application SHK20-04-16/4)

\section{Bibliographic references}

Blight, M.G.; Ruppel, E.K.; Schoenbauer, K.V. (2017). Sense of Community on Twitter and Instagram: Exploring the Roles of Motives and Parasocial Relationships. Cyberpsychology, Behavior, and Social Networking. № 20 (5): 314-319.

Boyd, D.M.; Ellison, N.B. (2007). Social Network Sites: Definition, History, and Scholarship. Journal of ComputerMediated Communication. № 13 (1): 210-230.

Demtsura, S.S.; Apukhtin, A.A.; Fedorova, K.A.; Sannikova, S.V.; Yakupov, V.R.; Rosliakova, S.V.; Lebedeva, T.N.; Pluzhnikova, I.I. (2018). Pricing policy in the field of marketing of educational services. Espacios. T. 39. № 62.

Demtsura, S.S.; Gordeeva, D.S. (2017). Labor price and investment in professional and qualification development of the company's employees. Research Azimuth: Economics and Management. T. 6. № 1 (18): 65-68.

Droppe, A.; Soderfeldt, B. (2010). What is academic quality? On the decline of academic autonomy. Sociologisk Forskning. Vol. 47. № 3: 57-74.

Evplova, E.V.; Yakupov, V.R.; Khabibullin, F.H.; Fedoseev, A.V .; Murygina, L.S. (2019). Making education mass: a sociological aspect. Baltic Humanitarian Journal. T. 8. № 3 (28): 56-60.

Explanatory note to the draft Federal Law No. 609096-5 "On Amendments to the Law of the Russian Federation" On Education "and the Federal Law" On Higher and Postgraduate Professional Education "(in terms of expanding the possibilities of using e-learning, including distance learning technologies). SPS "ConsultantPlus".

Field, J. (2008). Social Capital. London; New York: Routledge. 168 p.

Frison, E.; Eggermont, S. (2017). Browsing, Posting, and Liking on Instagram: The Reciprocal Relationships between Different Types of Instagram Use and Adolescents' Depressed Mood. Cyberpsychology, Behavior, and Social Networking. № 20 (10): 603-609.

Garcia-Martinez, A.J.; Gutierrez-Hita, C.; Sanchez-Soriano, J. (2012). Competitiveness, cooperation, and strategic interaction a classroom experiment on oligopoly. Revista internacional de sociologia. Vol. 70. № 1: 167-187.

Jafarzadeh-Kenarsari, F.; Pourghane, P. (2017). College students' experiences on smart phone technology usage: A qualitative content analysis study. Qualitative Report. Issue 22: 2864-2880.

King, R.B.; Mclnerney, D.M.; Watkins, D.A. (2012). Competitiveness is not that bad ... at least in the East: Testing the hierarchical model of achievement motivation in the Asian setting. International journal of intercultural relations. Vol. 36. № 3: 446-457. 
King, R.B.; Mclnerney, D.M.; Watkins, D.A. (2012). Competitiveness is not that bad ... at least in the East: Testing the hierarchical model of achievement motivation in the Asian setting. International journal of intercultural relations. Vol. 36. № 3: 446-457.

Kohn, A. (2017). Instagram as a naturalized propaganda tool: The Israel Defense Forces Web site and the phenomenon of shared values. Convergence. № 23 (2): 197-213.

Loginova, I.V. (2015). The quality of e-learning as a factor in the competitiveness of universities. E-learning in continuing education. № 1-2: 114-118.

Methodology for the use of distance learning technologies (distance learning) in educational institutions of higher, secondary and additional vocational education of the Russian Federation (approved by Order of the Ministry of Education of the Russian Federation of 18.12.2002 No. 4452). Russian newspaper. № 9. 18.01.2003.

Pike, J.; Bateman, P.; Butler, B. (2012). You Saw THAT?: Social Networking Sites, Self-Presentation, and Impression Formation in the Hiring Process. AMCIS. Available from: https://pdfs.semanticscholar.org/e013/31a6e0559783b2fc3650a4287a49499fb35d.pdf.

Popova, N.E. (2015). The use of multimedia in teaching: problems and contradictions. Novosibirsk State Pedagogical University Bulletin. № 3: 34-44.

Prigozhina, K.B.; Trostina, K.V. (2017). Virtual educational environment as a means of increasing the competitiveness of educational programs of the university. Education and Science. T. 19. № 5: 166-193.

Semenov, M. Yu. (2018). Virtual competitiveness: evaluating youth. Education and Science. T. 20. № 3: 100116.

Tang Shi-Ming, Shi Fang-Miao, Chen Xi. (2015). Career Competitiveness of College Gradu-ates: Issues and Problem Solving. International Conference on Sociology and Psychology (ICSP). Changsha: PEOPLES R CHINA: 171-175.

Veshchevatykh, T.A. (2007). Subjective approach to assessing the competitiveness of e-learning services. Bulletin of the Irkutsk State Economic Academy. № 2: 122-124.

Wakefield, M.A.; Rice, C.J. (2008) The impact of cyber communication on today's youth. (ACAPCD-14). Alexandria, VA: American Counseling Association.

Zhukova, N.V. (2006). The main directions of the formation of the competitiveness of universities in the region and the development of the e-learning system. Proceedings of higher educational institutions. Textile industry technology. № 5 (293): 16-20.

Esta obra está bajo una Licencia Creative Commons Attribución-NoCommercial 4.0 International

(cc) BY-NC 